\title{
Morphometric measurements to quantify the cerulein induced hyperstimulatory pancreatitis of rats under the protective effect of lectins *
}

\author{
Ludwig Jonas a,**, Ulrike Mikkat ${ }^{\mathrm{a}}$, Anke Witte ${ }^{\mathrm{a}}$, Uta Beckmann ${ }^{\mathrm{a}}$, Katrin Dölker ${ }^{\mathrm{a}}$, \\ Heike Weber ${ }^{\mathrm{b}}$, Christian Hahnel ${ }^{\mathrm{c}}$, Günther Kundt ${ }^{\mathrm{d}}$ and Horst Nizze ${ }^{\mathrm{a}}$ \\ ${ }^{a}$ Department of Pathology, University of Rostock, Rostock, Germany \\ ${ }^{\mathrm{b}}$ Department of Clinical Chemistry and Pathobiochemistry, University of Rostock, Rostock, Germany \\ ${ }^{\mathrm{c}}$ Department of Zoology, University of Rostock, Rostock, Germany \\ ${ }^{\mathrm{d}}$ Department of Medical Informatics and Biometry, University of Rostock, Rostock, Germany
}

Received 27 February 1998

Revised 8 September 1998

Accepted 26 January 1999

\begin{abstract}
In preceding papers we demonstrated an inhibitory effect of wheat germ agglutinin (WGA) and Ulex europaeus agglutinin (UEA) on the cholecystokinin (CCK) binding to the CCK receptor of rat pancreatic cells and also on the CCK induced $\mathrm{Ca}^{2+}$ release and $\alpha$-amylase secretion in vitro as well as on pancreatic secretion of intact rats in vivo. In the present study we show the same inhibitory effect of both lectins on the cerulein pancreatitis of rats. This acute pancreatitis was induced by supramaximal injections $(5 \mu \mathrm{g} / \mathrm{kg} / \mathrm{h}$ iv or $10 \mu \mathrm{g} / \mathrm{kg} / \mathrm{h}$ ip) of the CCK analogue cerulein in rats every hour. To monitor the degree of pancreatitis, we measured the number and diameter of injury vacuoles in the pancreatic acinar cells as one of the most important signs of this type of pancreatitis by light microscopic morphometry with two different systems on paraffin sections. Furthermore, the serum $\alpha$-amylase activity was measured biochemically. We found a correlation between the diameter of vacuoles inside the acinar cells and the serum enzyme activity up to $24 \mathrm{~h}$. The simultaneous ip administration of cerulein and WGA or UEA in a dosage of $125 \mu \mathrm{g} / \mathrm{kg} / \mathrm{h}$ for $8 \mathrm{~h}$ led to a reduction of vacuolar diameter from $13.1 \pm 2.0 \mu \mathrm{m}$ (cerulein) to $7.5 \pm 1.1 \mu \mathrm{m}$ (cerulein + WGA) or $7.2 \pm 1.3 \mu \mathrm{m}$ (cerulein + UEA). The serum amylase activity was reduced from $63.7 \pm$ $15.8 \mathrm{mmol} / \mathrm{l} \times \mathrm{min}$ (cerulein) to $37.7 \pm 11.8$ (cerulein $+\mathrm{WGA}$ ) or $39.4 ;+52.9 ;-31.1$ (cerulein + UEA-I). Both parameters allow the grading this special type of pancreatitis to demonstrate the protective effect of the lectins.
\end{abstract}

Keywords: Rat pancreas, cerulein, pancreatitis, lectin, morphometry, amylase, acinar vacuolization

\section{Introduction}

The cell membrane receptor for the peptide hormone cholecystokinin (CCK) and its analogue cerulein is highly glycosylated and therefore able to bind lectins [1-5]. The lectins wheat germ agglutinin (WGA) and Ulex europaeus agglutinin (UEA-I) were used for affinity chromatography to isolate the CCK-A

\footnotetext{
${ }^{*}$ This study was supported by the German Bundesministerium für Bildung und Forschung (BMBF, FKZ: 01 ZZ 102).

** Correspondence to: Dr L. Jonas, Department of Pathology, University of Rostock, Strempelstr. 14, P.O. Box 100888 , D-18055 Rostock, Germany. Tel.: +49 381494 5850; Fax: +49 3814945802.
} 
receptor of pancreatic acinar cells. Therefore, they should be able to alter the ligand-receptor interaction and the stimulus-secretion coupling of pancreatic cells. In preceding studies we were able to demonstrate an inhibitory effect of WGA on the ${ }^{125}$ I-CCK-8 binding to AR42J cells [6,7] and of both lectins on the CCK-8 induced $\mathrm{Ca}^{2+}$ release in rat pancreatic acinar cells [8]. Recently, we showed the inhibition on the CCK- 8 induced $\alpha$-amylase secretion of rat acini in vitro and of intact rats in vivo under the influence of both lectins [9]. The aim of the present study was to investigate the action of WGA and UEA-I on the hyperstimulatory cerulein pancreatitis in rats. This well-established animal model for a mild serous-interstitial acute pancreatitis is induced by supramaximal stimulation of rats by CCK or cerulein in dosages of 10-50 times above the optimal physiological value within 5-12 h [10-14]. This special pancreatitis is characterized by a strong vacuolization of acinar cells and an interstitial oedema without a necrotizing of the gland.

It is commonly accepted that the serum amylase levels, besides other pancreatic enzymes in the blood, are useful markers for the diagnosis of human acute pancreatitis, but are insufficient for grading and staging the pancreatic damage because of the late diagnosis and the strong necrotizing tendency [15]. Nevertheless, numerous authors used these parameters to study therapeutic or protective effects on the cerulein pancreatitis [16-19], they did not correlate the morphometrical quantified structural changes of the gland and serum enzyme values of rats. Therefore, we present here this interrelationship as well as a methodological contribution.

\section{Materials and methods}

Animals: Male rats of an inbred Lewis strain (LEW 1W, Department of Laboratory Animal Science, University of Greifswald, Karlsburg, Germany) with a body weight of about 180-220 g were used for the experiments. They were fed with rat standard diet and water ad libitum. Before manipulation they were starved for $12 \mathrm{~h}$ with free access to water.

Altogether 75 animals were divided into 5 experimental groups. Four rats were untreated and served as controls (group 1, control). Twenty animals received only cerulein to induce the cerulein pancreatitis (group 2, cerulein). Twenty rats were treated simultaneously with cerulein and WGA (group 3, cerulein + WGA simult.). Five animals were premedicated with WGA before treated with cerulein and WGA, simultaneously (group 4, cerulein + WGA pre. + simult.). Twenty five rats were treated with cerulein and UEA-I, simultaneously (group 5, cerulein + UEA-I).

Implantation of a jugularis catheter: For infusion of the hormone cerulein for $8 \mathrm{~h}$ (iv injection), we implanted a jugular catheter. The rats were anesthetized by a combination of Ketanest (Parke-Davis, Berlin, Germany) and Rompun (Bayer, Leverkusen, Germany). A polyethylen catheter was inserted into the left jugular vein and fixed by ligation. The catheter was taken out of the back skin and mounted on a carroussel on the top of a solitary cage. The animals were only used $24 \mathrm{~h}$ after implantation of the catheter. Because of the stress caused by anesthesia and the operation, for most experiments we used the ip administration of cerulein.

The iv infusions with cerulein were only carried out for comparison to test the reproducibility of the time course of cerulein pancreatitis ( 7 animals).

Induction of an acute pancreatitis: The cerulein pancreatitis was induced by intravenous (iv) or intraperitoneal (ip) injections of cerulein (Sigma, Deisenhofen, Germany) in a dosage of $5 \mu \mathrm{g} / \mathrm{kg} / \mathrm{h}$ (iv) or $10 \mu \mathrm{g} / \mathrm{kg} / \mathrm{h}$ (ip), respectively, for $8 \mathrm{~h}$. The induction of this hyperstimulatory pancreatitis was verified by 
morphological (light and electron microscope) examination of the pancreatic glands and by biochemical measurements of serum $\alpha$-amylase activity.

Lectins: Wheat germ agglutinin (WGA) and Ulex europaeus agglutinin (UEA I) were obtained from EY Laboratories (San Mateo, Ca, USA).

Administration of cerulein and lectin: Cerulein was dissolved in physiological $\mathrm{NaCl}$ solution $(100 \mu \mathrm{g}$ cerulein $/ \mathrm{ml}$ ) and injected intravenously into a jugular catheter by an infusion pump (Vial medical, Se 400, Becton Dickinson, Vial, St. Etienne, France) in a dosage of $5 \mu \mathrm{g} / \mathrm{kg} / \mathrm{h}$ or intraperitoneally by one injection with a syringe in a dosage of $10 \mu \mathrm{g} / \mathrm{kg}$ every hour. The cerulein pancreatitis developed fully after $8 \mathrm{~h}$. Longer administration of cerulein did not lead to stronger vacuolization and higher serum amylase levels. Therefore, we used $8 \mathrm{~h}$ as the experimental time for all following studies, but the course of the cerulein pancreatitis was verified up to $24 \mathrm{~h}$.

Every hour simultaneously with cerulein, WGA or UEA-I was administered by injection into the peritoneal cavity for $8 \mathrm{~h}$ in a dosage of $125 \mu \mathrm{g} / \mathrm{kg} / \mathrm{h}$. Five animals were premedicated for $1 \mathrm{~h}$ with WGA by a single injection, followed by the simultaneous administration of the hormone and the lectin.

Collecting of the samples: After $8 \mathrm{~h}$ the animals were anesthetized by Ketanest in a dosage of 125 $\mathrm{mg} / \mathrm{kg}$ and sacrifized by the method of heart puncture. Blood was collected by heart puncture and used for the biochemical estimation of the pancreatic $\alpha$-amylase activity in the serum.

The pancreata of all animals were collected for morphological examination.

Measurement of $\alpha$-amylase: Serum $\alpha$-amylase activity $(\mathrm{mmol} / \mathrm{l} \times \mathrm{min})$ of all animals was measured by an automated analytical system EPOS 5060 (Eppendorf, Germany) with the commercial $\alpha$-amylase test kit PNP (Boehringer, Mannheim, Germany).

Light microscopy: Pancreatic tissue was fixed in $4 \%$ buffered neutral formaldehyde for $24 \mathrm{~h}$, embedded in paraffin, sectioned and stained by hematoxylin-eosin (HE). Paraffin sections after staining by HE or semithin sections of epoxy resin embedded tissue after staining with toluidin blue were examined in a light microscope Jenamed (Zeiss, Jena, Germany). Semithin sections were used for electron microscopy to select representative areas or for light microscopy to make high resolution micrographs.

Electron microscopy: Samples of pancreatic tissue were dissected into small blocks with a razor-blade, fixed with $4 \%$ glutaraldehyde in $0.1 \mathrm{M}$ sodium phosphate buffer, $\mathrm{pH} 7.0$ for $1 \mathrm{~h}$, washed in the same buffer and postfixed with $1 \% \mathrm{OsO}_{4}$. The samples were dehydrated, embedded, and sectioned in the usual manner. Semithin $(0.5-1.5 \mu \mathrm{m})$ or ultrathin sections $(50-100 \mathrm{~nm})$ were prepared with a LKB-Ultrotom III (LKB, Stockholm, Sweden). Ultrathin sections were examined after obtaining contrast with uranyl acetate and lead citrate in an electron microscope EM 902 A (Zeiss, Oberkochen, Germany).

Morphometric examination: To quantify the number and diameter of acinar cell vacuoles, we used two different morphometric systems: (1) semi-automatic system consisting of the light microscope Nikon Diaphot 300 with an objective $20 \times$ (Planapo/0.75), a video camera RCA (Newicon, USA) and a Silicon Graphics Work station with the Inter Vision software package 2D analysis (Noran, USA) (Department of Zoology, Dr C. Hahnel), (2) automatic system Kontron 300 (Kontron Electronics Munich, Germany) with a light microscope Axiolab (Zeiss, Germany), a CP Achromat objective $20 \times$ and a CCD Video Camera BC 6 (AVT-Horn) (Department of Pathology, K. Dölker). For the semi-automatic system, the monitor display was calibrated with a commercial micrometer test plate. The area of one pixel was determined in $\mu \mathrm{m}^{2}$. The pixel area was $0.43 \mu \mathrm{m}$. For morphometric estimations, we used only paraffin sections, stained with HE. The diameter of all vacuoles inside 5 different, randomly selected areas of the 
pancreatic cross sections of all experimental animals was marked with a cursor by hand and quantified by computer. Per section, at least 200 vacuoles were measured. The automatic morphometry was used in addition to control the results of the semi-automatic method and to count all vacuoles including the small vesicles. The automatic system was also calibrated by a test scale, as described above.

Statistical methods: Means of normally distributed data with similar variance were compared by Student's $t$-test. The data of group 5 (not normally distributed) are expressed as median $+25 \%$. This $p$ value was calculated by the Wilcoxon test. A $p<0.05$ was considered to be significant [20]. Furthermore, we determined the Spearman correlation coefficient between the diameter of acinar vacuoles and the serum amylase levels to determine the linear regression.

\section{Results}

\subsection{Light microscopy of cerulein pancreatitis}

The histological examination of the pancreatic glands of all cerulein treated animals revealed a strong interstitial oedema, as also seen macroscopically in an enlargement of the glands with fluid filled spaces between the pancreatic lobules. Additionally, there was a strong cytoplasmic vacuolization of exocrine acinar cells, which gave the tissue a Swiss cheese-like structure (Fig. 1a). When the cerulein pancreatitis was induced by iv infusion of cerulein through a jugularis catheter, the vacuolization of exocrine acinar cells was nearly homogeneously distributed over the whole gland. After ip administration of cerulein the

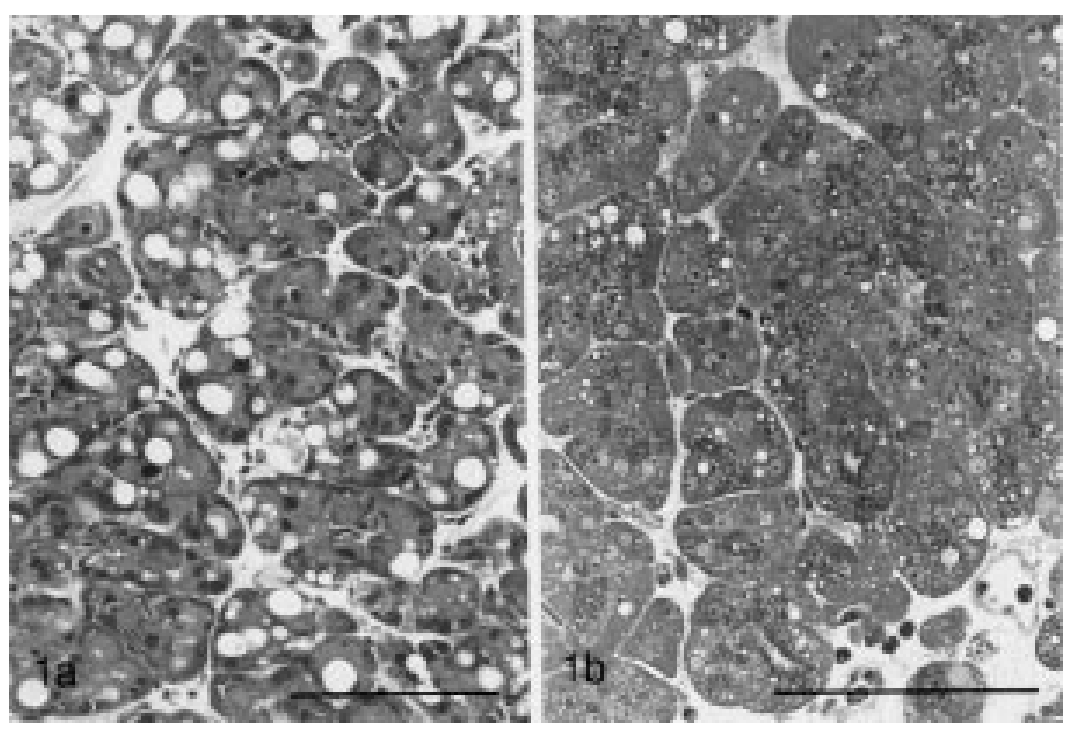

Fig. 1. (a) Semithin section of rat pancreatic exocrine tissue 8 hours after the induction of cerulein pancreatitis; ip application of cerulein $(10 \mu \mathrm{g} / \mathrm{kg} / \mathrm{h})$; toluidine blue staining; swiss cheese-like structure of pancreatic tissue, numerous big vacuoles are seen in the acinar cells, sometimes larger than the nucleus; some vacuoles reach a diameter of more than $20 \mu \mathrm{m}$; corresponding serum $\alpha$-amylase activity of $69.6 \mathrm{mmol} / \mathrm{l} \times \mathrm{min}$ ) and a mean diameter of vacuoles of $15.7 \pm 5.4 \mu \mathrm{m}$ in this special case $(340 \times)$. (b) WGA effect on the cerulein pancreatitis of rats; semithin section of rat pancreatic tissue 8 hours after simultaneous ip application of cerulein $(10 \mu \mathrm{g} / \mathrm{kg} / \mathrm{h})$ and WGA $(125 \mu \mathrm{g} / \mathrm{kg} / \mathrm{h})$; toluidin blue staining; numerous small vacuoles of about $0.5-4 \mu \mathrm{m}$ and some larger ones of about $10-15 \mu \mathrm{m}$ are visible in the acinar cells; in this animal a serum $\alpha$-amylase activity of $26.3 \mathrm{mmol} / \mathrm{l} \times \mathrm{min}$ and a mean diameter of vacuoles of $6.2 \pm 2.2 \mu \mathrm{m}$ were measured $(410 \times)$. 
strongest changes were found in the peripheral parts of the gland and along the interlobular spaces. The vacuolization occurred after $2 \mathrm{~h}$ and reached a maximum between 8 and $12 \mathrm{~h}$. Afterwards this alteration decreased slowly within $24 \mathrm{~h}$. On account of the full induction of cerulein pancreatitis with a strong vacuolization and the highest serum amylase levels after $8 \mathrm{~h}$, we used this time for most of the following experiments.

The animals, treated simultaneously by cerulein and WGA for $8 \mathrm{~h}$ showed a smaller vacuolization and a diminished oedema (Fig. 1b). Additional premedication with WGA for $1 \mathrm{~h}$ or simultaneous UEA-I treatment led to similar results. There seemed to be two different populations of vacuoles inside the acinar cells, which were influenced by cerulein and lectin. Whereas the large vacuoles were diminished in number and size, there were numerous additional small vesicles. The large vacuoles were mostly found in the supranuclear area and the small vacuoles, presumably endocytotic vesicles, occurred more basolaterally in the cytoplasm of acinar cells.

Macroscopically or light microscopically, we never observed haemostasis or microthrombs in the pancreatic blood vessels nor in other abdominal organs after lectin administration, which could serve as a sign of haemagglutinating activity of lectins.

\subsection{Electron microscopy}

After $8 \mathrm{~h}$ of cerulein administration, the acinar cells showed large vacuoles in the cytoplasm, which reached a size larger than the nucleus (Fig. 2a, see also morphometric results). They occurred as mostly solitary, but sometimes numbered three or more per cell. The contents of these large vacuoles was electron lucent, often mixed with residues of membranes and zymogen granules. Sometimes almost intact zymogen granules inside the vacuoles could be detected (Fig. 2a, insert).

After administration of lectins, these vacuoles were markedly reduced in number and size (Fig. 2b, see also morphometric results), or only the small vesicles with a diameter of about $0.3 \mu$ m were seen (Fig. $2 \mathrm{~b}$, insert). In most cases these vacuoles in the lectin treated acinar cells showed an electron transparent content without cell debris. Sometimes we observed endocytose figures on the basal cell membrane in form of invaginations and microvesicles. Their membranes were never coated by clathrin. The small vesicles were preferentially observed in lectin treated animals.

\subsection{Biochemical results}

To monitor the cerulein pancreatitis, we measured the serum $\alpha$-amylase activities of all animals in comparison to the morphometric estimations. Figure 3 demonstrates the time course of development of cerulein pancreatitis and blood serum amylase levels $(\mathrm{mmol} / \mathrm{l} \times \mathrm{min})$ over the period of $24 \mathrm{~h}$ with iv or ip application of cerulein. In both cases the serum amylase values reached a maximum after $8 \mathrm{~h}$. This time was found also as the point of strongest macroscopic and microscopic changes of the pancreatic gland. The cerulein pancreatitis was fully developed after $8 \mathrm{~h}$. Longer administration of cerulein did not lead to higher serum amylase levels and stronger vacuolization of acinar cells. Both methods of cerulein administration showed similar serum amylase activities. Therefore, we used $8 \mathrm{~h}$ as the experimental period and an ip administration of cerulein for all following studies.

Figure 4 shows the mean amylase levels of the animals in the different experimental groups after ip administration of cerulein. The $\alpha$-amylase activity of untreated animals was very low $(2.7 \pm 0.9$ $\mathrm{mmol} / \mathrm{l} \times \min$; group 1). Cerulein administration in the dosage of $10 \mu \mathrm{g} / \mathrm{kg} / \mathrm{h}$ over a period of $8 \mathrm{~h}$ led to more than a 20 fold increase in serum amylase activity (63.7 \pm 15.8 ; group 2$)$. Both lectins showed an 

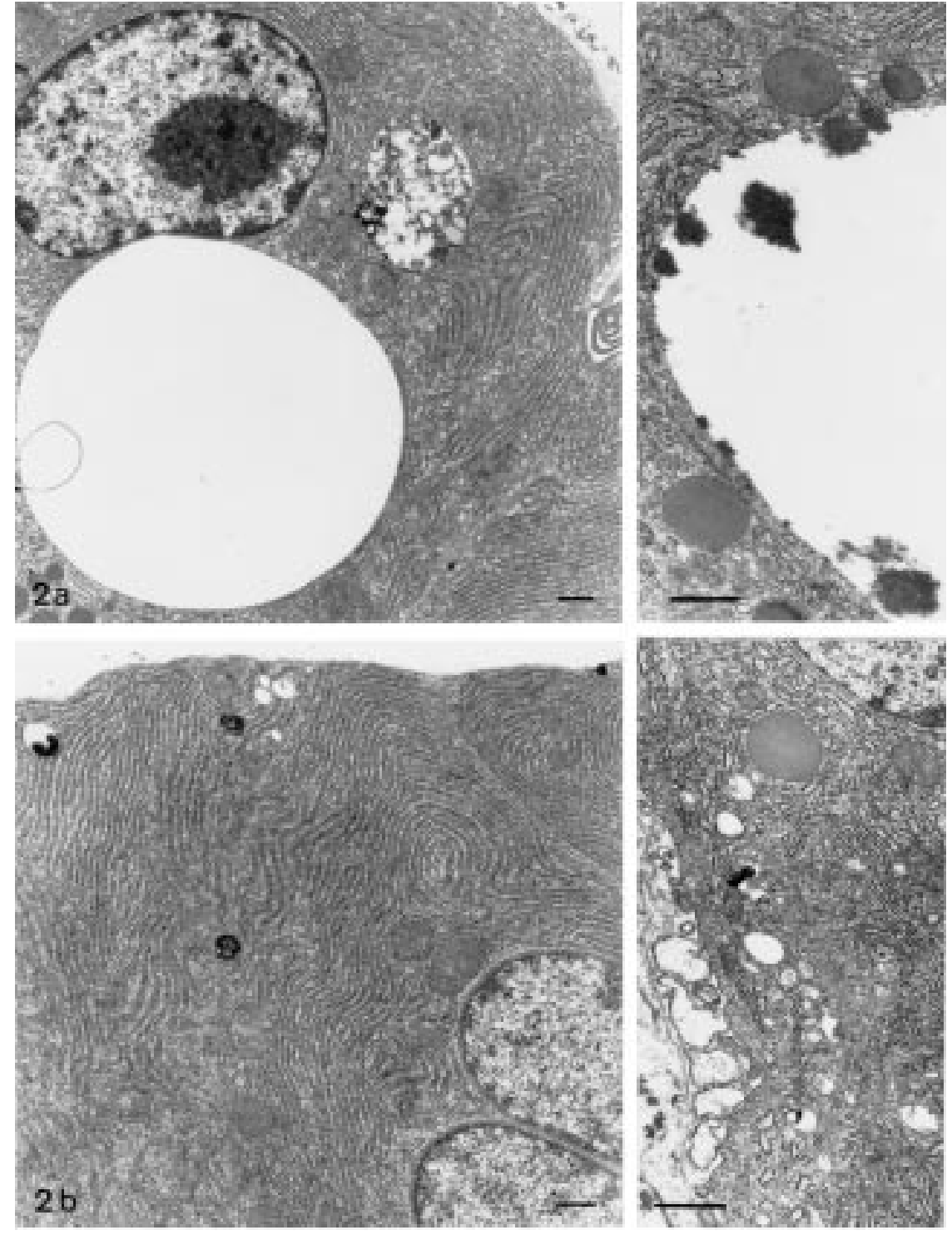

Fig. 2. (a) Rat pancreatic acinar cell 8 hours after cerulein application; electron microscopy; cell with a large rounded vacuole, containing an electron lucent contents $(7000 \times)$. Insert: border between the cytoplasm and the injury vacuole; some intact zymogen granules in the cytoplasm and numerous secreted granules in the vacuole, resolving by hydration $(12000 \times)$. (b) Rat pancreatic acinar cell $8 \mathrm{~h}$ after simultaneous cerulein and WGA administration; electron microscopy; cell without large injury vacuoles; a few small vesicles on the basal cell surface $(7000 \times)$. Insert: numerous small vesicles, presumably endocytic vesicles, on the basolateral border of the cell $(12000 \times)$.

inhibitory effect on the $\alpha$-amylase level. After simultaneous administration of the hormone and WGA, the serum enzyme values were significantly decreased to about $40 \%$ (compare group 2 and 3;63.7 \pm 15.8 versus $37.7 \pm 11.8$ ). The pre-administration with WGA $1 \mathrm{~h}$ before simultaneous administration of cerulein and WGA showed the strongest effect (compare group 2 and 4; $63.7 \pm 15.8$ versus $28.8 \pm$ 8.5). Simultaneous injections of cerulein and UEA reduced the amylase level to about $62 \%$; (compare $63.7 \pm 15.8$ versus $39.4,+52.9,-31.1$, non-normally distributed, group 5 ). The differences between the 


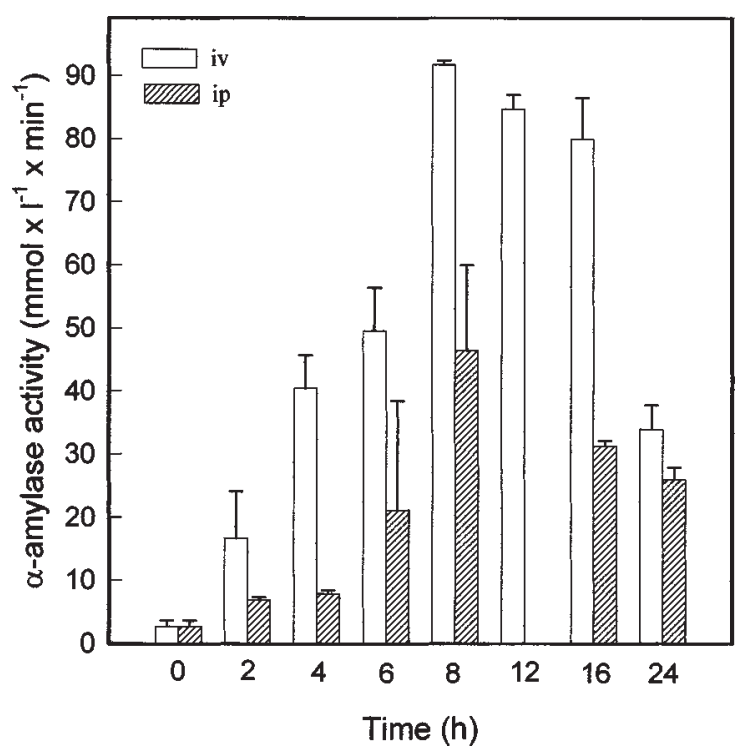

Fig. 3. Time course of $\alpha$-amylase activity (mmol/l $\times \min )$ in the serum of rats after iv medication of cerulein $(5 \mu \mathrm{g} / \mathrm{kg} / \mathrm{h})$ through a jugularis catheter (white columns) and after ip application of cerulein ( $10 \mu \mathrm{g} / \mathrm{kg} / \mathrm{h}$ ) (lining columns). The development of cerulein pancreatitis after injections of cerulein every hour was monitored on the serum amylase activities for a period of $24 \mathrm{~h}$. Maximal values were reched after $8 \mathrm{~h}$. Thereafter serum amylase levels decreased slowly up to $24 \mathrm{~h}$ in spide of further supramaximal stimulation by cerulein. The time of highest serum amylase values corresponds with the strongest interstitial oedema of the pancreas and highest vacuolization of pancreatic acinar cells.

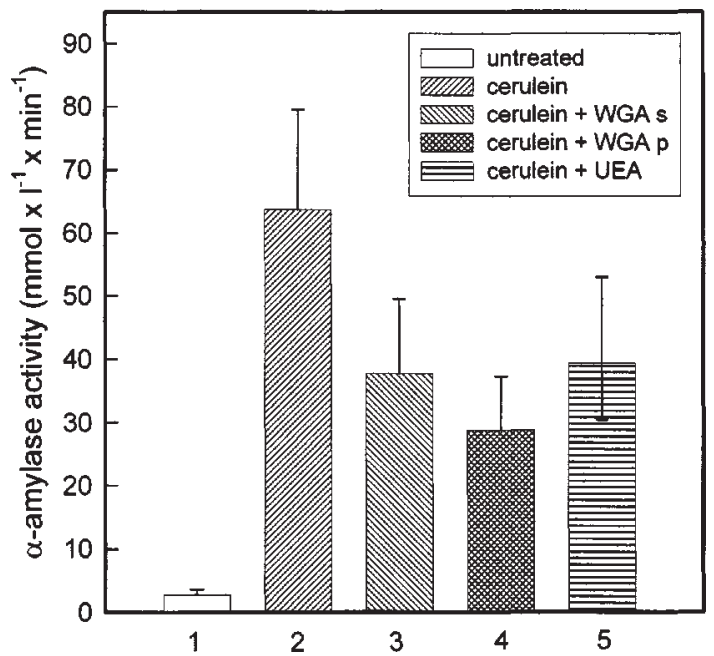

Fig. 4. The $\alpha$-amylase activity $(\mathrm{mmol} / 1 \times \mathrm{min})$ in the serum of rats after induction of cerulein pancreatitis and ip administration of cerulein and lectins. The results are expressed as mean \pm standard derivation (SD) (groups 1-4, normally distributed) or median (group 5, non-normally distributed). Serum amylase activity of untreated $(\mathrm{NaCl}$ ) animals (group 1), cerulein treated rats (group 2) and lectin treated animals (groups 3, 4, 5). Significant decrease of enzyme levels by simultaneous WGA administration (compare groups 2 and $3, p<0.001$ ). Strongest inhibitory effect after additional WGA premedication (compare groups 2 and $4, p<0.001$ ). WGA showed a stronger decreasing effect on the amylase value in the serum than UEA-I (compare groups 2 and $5, p<0.001$ ). The results of groups $1-4$ are expressed as mean $\pm \mathrm{SD} ; p$ values were calculated by $t$-test (normally distributed). The data of group 5 (non-normally distributed) are expressed as median $+25 \%$. This $p$ value was calculated by Wilcoxon test. 
Table 1

Morphometric estimated diameter of acinar injury vacuoles $(\mu \mathrm{m})$ after cerulein pancreatitis, with or without simultaneous lectin administration

\begin{tabular}{lcr}
\hline & Mean diameter $\pm \mathrm{SD}(\mu \mathrm{m})$ & $n^{\mathrm{a}}$ \\
\hline Cerulein & $13.06 \pm 2.03$ & 13 \\
Cerulein $+\mathrm{WGA}^{\mathrm{b}}$ & $7.51 \pm 1.09$ & 7 \\
Cerulein $^{\mathrm{C}} \mathrm{UEA}^{\mathrm{c}} \mathrm{I}^{\mathrm{c}}$ & $7.23 \pm 1.32$ & 17 \\
\hline
\end{tabular}

${ }^{a} n$ gives the number of animals.

${ }^{\mathrm{b}}$ WGA: wheat germ agglutinin.

${ }^{\mathrm{c}}$ UEA-I: Ulex europaeus agglutinin.

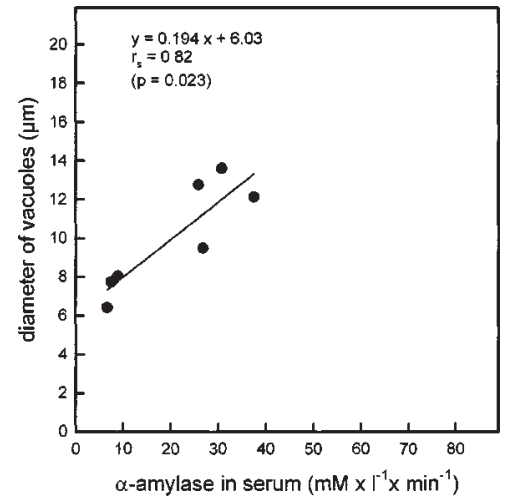

(a)

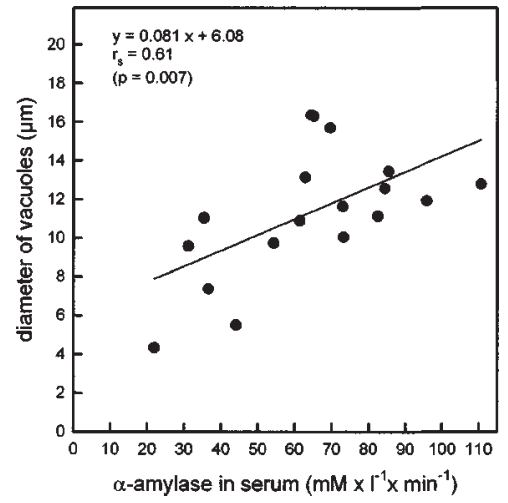

(b)

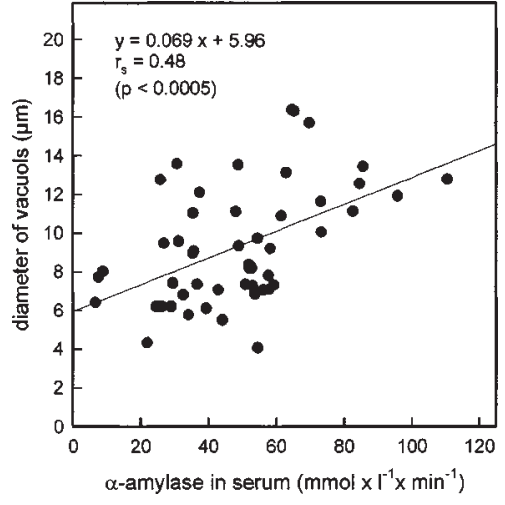

(c)

Fig. 5. Correlation between $\alpha$-amylase activity in the serum $(\mathrm{mmol} / \mathrm{l} \times \mathrm{min})$ and morphometric estimated diameter of acinar injury vacuoles $(\mu \mathrm{m})$; (a) regression line after iv medication of only cerulein through a jugularis catheter, $n=7$; (b) regression line after ip medication of only cerulein, $n=18$; (c) regression line after iv or ip medication of cerulein with or without simultaneous administration of WGA or UEA-I, $n=51$.

different experimental groups were highly significant (Fig. 4). As revealed in preliminary experiments, both lectins alone had no effect on the $\alpha$-amylase values in the blood of animals (data not shown). Furthermore, the same influence of both lectins was seen in experiments, where the animals received iv infusions of $5 \mu \mathrm{g} / \mathrm{kg} / \mathrm{h}$ cerulein and $125 \mu \mathrm{g} / \mathrm{kg}$ lectin, intraperitoneally (data not shown).

The level of serum $\alpha$-amylase of animals up to $8 \mathrm{~h}$ of cerulein administration seemed to coincide with the degree of morphologic changes of cerulein pancreatitis, especially with the degree of acinar vacuolization. Therefore, we used morphometry for the quantification of this injury.

\subsection{Morphometric measurements}

To quantify the vacuolization in acinar cells as one of the most characteristic signs of the cerulein pancreatitis, we measured the diameter of the vacuoles inside the cytoplasm of exocrine cells first by a semi-automatic system of morphometry. The estimated values are shown in Table 1. For the only cerulein treated animals (group 2, Fig. 4) we found a diameter of vacuoles of $13.06 \pm 2.03 \mu \mathrm{m}$, whereas the simultanous administration of cerulein and lectin led to a reduction of this value to nearly the half $(7.51 \pm 1.09 \mu \mathrm{m}$ for cerulein + WGA; group 3, Fig. 4), or $(7.23 \pm 1.32 \mu \mathrm{m}$ for cerulein + UEA, group 5, Fig. 4). 


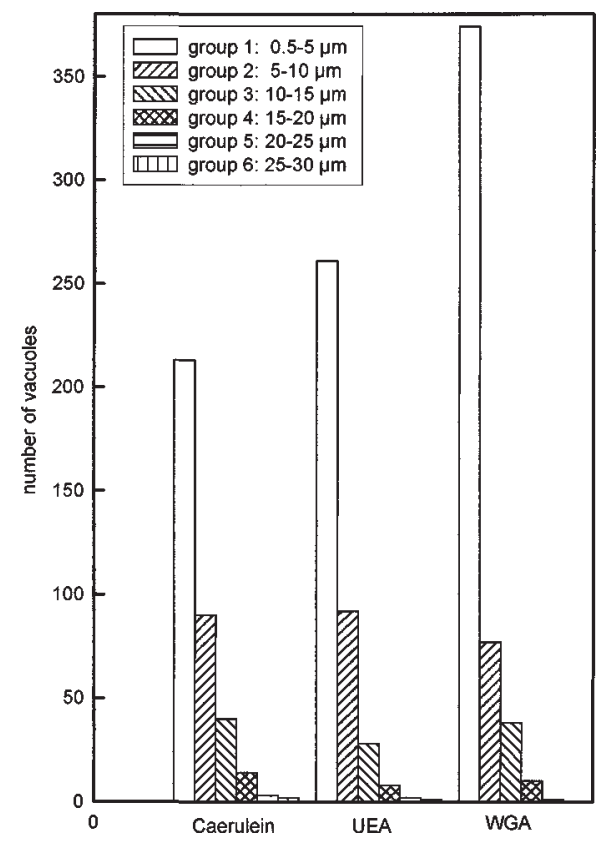

Fig. 6. Classification of the diameter of vacuoles inside pancreatic acinar cells after ip medication of cerulein with or without simultaneous lectin administration. WGA and UEA; increase of the number of smallest vacuoles (white column), presumably endocytic vesicles (group 1, 0.5-5 $\mu \mathrm{m}$ ) under lectin administration, whereas both lectins diminished the number of largest injury vacuoles (group 5, 20-25 $\mu \mathrm{m}$; group 6, 25-30 $\mu \mathrm{m}$ ).

As revealed by comparison of serum amylase values with the histologic estimation of the severity of cerulein pancreatitis, there seemed to be a relation between diameter of acinar vacuoles and serum enzyme levels. Therefore, we tested the correlation between both values. Figure 5a shows this correlation after iv medication of only cerulein, Fig. $5 \mathrm{~b}$ after ip administration of only cerulein, Fig. $5 \mathrm{c}$ after simultaneous medication of cerulein (iv or ip) and WGA or UEA. The correlation between both values was found to be significant according to the Spearman correlation test $\left(r_{\mathrm{S}}=0.82, p=0.023\right.$, iv; $r_{\mathrm{S}}=0.61$, $p=0.007$, ip; $r_{\mathrm{S}}=0.48, p<0.0005$, iv $+\mathrm{ip}$, cerulein + lectin). The strongest correlation is visible at only iv medicated cerulein animals (Fig. 5a), but it is also demonstrable in ip injected cerulein rats (Fig. 5b) or in all measured cases (iv or ip cerulein medication with or without lectin administration, Fig. 5c).

To verify the measurements of the semiautomatic morphometric system, we used an automatic system for a second time. We were able to reproduce the mean values of injury vacuoles in the acinar cells. Additionally, we divided the vacuoles and vesicles into 6 groups (Fig. 6). Whereas the largest vacuoles (groups 5 and 6, diameter 20-25, and 25-30 $\mu \mathrm{m}$, respectively) are strongly diminished or totally disappear under the influence of WGA and UEA, the smallest vesicles (group 0.1-5 $\mu \mathrm{m}$ ) were significantly increased (Fig. 6, see also light and electron microscope results).

\section{Discussion}

Cerulein pancreatitis of rats and other mammals is a well established animal model for a mild serous interstitial pancreatitis of man [10-15] and is used for testing several substances on this special acute 
pancreatitis [16-19]. Especially, CCK antagonists were studied for their therapeutic or protective relevance [21-25]. The monitoring of cerulein pancreatitis is a problem similar to that of human acute pancreatitis [15,22]. Most authors used the serum amylase activity and of other pancreatic enzymes in the blood to measure any influence on this model. Besides biochemical parameters, scoring systems were used to grade the histological changes of injury and for grading cerulein pancreatitis [17,19,22]. In a preceding paper we also used a histological scoring system beside the serum amylase values to grade the cerulein pancreatitis under the influence of hyperthermia induced HSP 70 [26]. In this case the vacuolization of pancreatic acinar cells and the interstitial oedema of the gland seemed to coincide with the $\alpha$-amylase activities in the serum of animals. The scoring system is only a semiquantitative method for grading. In the present paper we measured the degree of acinar vacuolization as one of the most impressive signs of cerulein pancreatitis by morphometry. Both morphometric systems gave similar results. The size of vacuoles correlate with the serum $\alpha$-amylase levels of animals up to $24 \mathrm{~h}$ of cerulein administration. The comparison between both kinds of cerulein medication showed that the iv infusion of cerulein revealed a more homogeneous vacuolization of the gland and a better correlation between both parameters than the ip injections.

Both morphometric systems counted the number and size of vacuoles. The semi-automatic method is more time consuming. The automatic system was much more effective to measure all classes of vacuoles. We classified them into 6 groups. So it was observable that only the largest vacuoles (group 6, 30$25 \mu \mathrm{m}$ and group 5, 25-20 $\mu \mathrm{m}$ ) were diminished under the influence of both lectins, whereas the smallest vesicles (group 1, diameter 5-0.1 $\mu \mathrm{m}$ ), however, were increased. Therefore, we consider only the large acinar vacuoles as a sign of injury, caused by hyperstimulation, whereas the small vesicles of the group 1 seem to be an expression for a strong internalization of lectins. This assumption is supported by our earlier studies on the uptake of FITC or colloidal gold labelled WGA or UEA from the peritoneal cavity in the pancreatic acinar cells of rats 27. In this study it was possible to monitor the binding of lectins to the basolateral cell membrane, the endocytosis by small uncoated vesicles, their disintegration in lysosomes and the extrusion into the secretion lumen.

In the present paper, we were able to demonstrate a protective effect of WGA and UEA-I on the cerulein pancreatitis, which is expressed by a significant decrease of serum $\alpha$-amylase levels and vacuolization of pancreatic acinar cells. Furthermore, we observed a reduction of the interstitial oedema under the medication with WGA or UEA-I. The interstitial oedema was not measured in the present study, but it would be useful to quantify it also morphometrically. The inhibitory effect of both lectins is in good accordance with our previous results. In preceding papers we described a dosage-dependent inhibition of WGA on ${ }^{125}$ I-CCK-8 binding on pancreatic AR42J cells and of WGA and UEA-I on CCK8 induced $\mathrm{Ca}^{2+}$ release and $\alpha$-amylase secretion on isolated rat pancreatic acini [6-9]. Furthermore, the in vivo secretion of healthy rats was significantly decreased after simultaneous ip administration of cerulein and both lectins in respect to the volume secretion and $\alpha$-amylase output [9]. Additionally, both lectins showed an inhibitory effect on the CCK- 8 stimulated $\alpha$-amylase secretion of AR42J cells [unpublished data]. The lectinic action of WGA and UEA-I was inhibited by preabsorption with their specific sugars $\mathrm{N}$-acetylglucosamine or $\mathrm{N}, \mathrm{N}^{\prime}, \mathrm{N}^{\prime \prime}$-triacetylchitotriose for WGA and $\alpha$-L-fucose for UEA-I [6-9].

Neither lectins showed any cytotoxic activity in living rat pancreas, isolated rat pancreatic acinar cells or AR42J cell cultures $[9,26,27]$. Conversely, WGA and UEA-I showed a protective effect on AR42J cells with respect to a higher degree of differentiation in a dosage of $25 \mu \mathrm{g} / \mathrm{ml}$, used for the inhibition experiments. In electron microscopy these cell cultures showed well differentiated cells with numerous zymogen granules under the influence of both lectins up to $24 \mathrm{~h}$, whereas in controls without lectin only 
a few immature enzyme granules could be seen. We did not observe any signs of apoptosis, necrosis or a mitogenic effect in these cell cultures.

The exact mechanism of these lectin effects still remains unclear, but the binding studies and in vitro experiments seem to demonstrate a competition between WGA or UEA-I and CCK-8, respectively, cerulein on the CCK-A receptor. Besides a direct action of lectins on the pancreas, indirect secondary or tertiary effects via blood, hormone or immune system are also possible. Because haemostasis or microthrombi in the pancreatic blood vessels or other abdominal organs after intraperitoneal administration of WGA or UEA-I were never observed, the possible malperfusion of the pancreatic gland by the ability of lectins to cause haemagglutination can be excluded. Furthermore, we never observed any injury or mortality of rats by intraperitoneal administration of these lectins in dosages up to $250 \mu \mathrm{g} / \mathrm{kg} / \mathrm{h}$. Preexperiments for haemagglutination in vitro and mortality of rats in vivo showed that the dosages of both lectins used in these experiments were far from the danger level.

In conclusion, it is suggested that vacuole size correlates well with serum $\alpha$-amylase level in cerulein pancreatitis. WGA and UEA-I appear to protect against this pancreatitis. The value of morphometric assessment of intracellular vacuole size for grading of cerulein pancreatitis is obvious. Further morphometric studies should analyse the validity of interstitial oedema with respect to a correlation to the serum amylase activity to grade this injury.

\section{Acknowledgements}

This study was supported by the German Bundesministerium für Bildung und Forschung (BMBF, FKZ: 01 ZZ 102). We thank Kathrin Sievert from the Experimental Research Centre of the School of Medicine of the University of Rostock for the technical assistance in animal handling.

\section{References}

[1] R.K. Pearson, L.J. Miller, E.M. Hadac and S.P. Powers, Analysis of the carbohydrate composition of the pancreatic plasmalemmal glycoprotein affinity labeled by short probes for the cholecystokinin receptor, J. Biol. Chem. 262 (1987), $13850-13856$.

[2] R. Santer, I.K. Leung, P. Alliet, E. Lebenthal and P.C. Lec, The role of carbohydrate moieties of cholecystokinin receptors in cholecystokinin octapeptide binding: alteration of binding data by specific lectins, Biochim. Biophys. Acta 1051 (1990), $78-83$.

[3] J. Szecowka, G. Hallden, I.D. Goldfine and J.A. Williams, Purification of the pancreatic cholecystokinin receptor, Regul. Pept. 24 (1989), 215-224.

[4] S.A. Wank, R. Harkins, R.T. Jensen, H. Shapira, A. DeWeerth and T. Slattery, Purification, molecular cloning, and functional expression of the cholecystokinin receptor from rat pancreas, Proc. Natl. Acad. Sci. USA 89 (1992), 3125-3129.

[5] S.A. Wank, J.R. Pisegna and A. DeWeerth, Cholecystokinin receptor family, Ann. N. Y. Acad. Sci. 713 (1994), 449-465.

[6] I. Damm, U. Mikkat and L. Jonas, ${ }^{125}$ I-CCK-8 binding studies on AR42J rat pancreatic cells under the influence of lectins, Pancreas (in preparation).

[7] U. Mikkat, I. Damm, H. Weber and L. Jonas, The influence of the lectin wheat germ agglutinin (WGA) on the binding of ${ }^{125} \mathrm{I}$-CCK-8s to rat pancreatic cells and its effect on the CCK-8s stimulated $\alpha$-amylase secretion in vitro, Eur. J. Cell. Biol. 42(Suppl.) (1996), 138.

[8] L. Jonas, G. Fulda, I. Damm, B. Nebe and J. Rychly, Flow cytometric measurements of intracellular Ca ${ }^{++}$mobilization in isolated rat pancreatic acinar cells after hormone stimulation and action of lectins, Acta Histochem. 97 (1995), 81-88.

[9] U. Mikkat, I. Damm, G. Schröder, K. Schmidt, C. Wirth, H. Weber and L. Jonas, Effect of the lectins wheat germ agglutinin (WGA) and Ulex europaeus agglutinin (UEA-I) on the $\alpha$-amylase secretion of rat pancreas in vitro and in vivo, Pancreas 166 (1998), 529-538.

[10] M. Lampel and H.F. Kern, Acute interstitial pancreatitis in the rat induced by excessive doses of a pancreatic secretagogue, Virchows Arch. Pathol. Anat. 373 (1977), 97-117. 
[11] G. Adler, T. Hupp and H.F. Kern, Course and spontaneous regression of acute pancreatitis in the rat, Virchows Archiv A Pathol. Anat. Histol. 382 (1979), 31-47.

[12] G. Scheele, G. Adler and H.F. Kern, Exocytosis occurs at the lateral plasma membrane of the pancreatic acinar cell during supramaximal secretagogue stimulation, Gastroenterology 92 (1987), 345-353.

[13] A.K. Saluja, M. Saluja, H. Printz, A. Zavertnik, A. Sengupta and M.L. Steer, Experimental pancreatitis is mediated by low-affinity cholecystokinin receptors that inhibit digestive enzyme secretion, Proc. Natl. Acad. Sci. USA 86 (1989), 8968-8971.

[14] F.S. Gorelick, G. Adler and H.F. Kern, Cerulein-induced pancreatitis, in: The Pancreas. Biology, Pathobiology and Disease, V.L.W. Go, E.P. DiMagno, J.D. Gardner, E. Lebenthal, H.A. Reber and G.A. Scheele, eds, Raven Press, New York, 1993, pp. 501-526.

[15] M.D. Levitt and J.H. Eckfeld, Diagnosis of acute pancreatitis, in: The Pancreas. Biology, Pathobiology and Disease, V.L.W. Go, E.P. DiMagno, J.D. Gardner, E. Lebenthal, H.A. Reber and G.A. Scheele, eds, Raven Press, New York, 1993, pp. 613-635.

[16] S. Tani, M. Otsuki, H. Itoh, T. Nakamura, M. Fujii, Y. Okabayashi, T. Fujisawa and S. Baba, The protective effect of the trypsin inhibitor uristatin on cerulein-induced acute pancreatitis in rats, Pancreas 33 (1988), 471-476.

[17] L. Buscail, I. Bussenot, M. Bouisson, F. Senegas-Balas, C. Bertrand, D. Balas, N. Vaysse and A. Ribet, Protective effect of misoprostol, a synthetic prostaglandin $\mathrm{E}_{1}$ analog, on cerulein-induced acute pancreatitis in rats, Pancreas 5 (1990), 171-176.

[18] R. Pescador, M.A. Manso, A.J. Rebollo and I. De Dios, Effect of chronic administration of hydrocortisone on the induction and evolution of acute pancreatitis induced by cerulein, Pancreas 11 (1995), 165-172.

[19] R. Abe, T. Shimosegawa, K. Kimura, A. Takasu, M. Koizumi and T. Toyota, Lipopolysaccharide-induced desensitization to pancreatic oedema formation in rat cerulein pancreatitis, Pancreas 16 (1985), 39-544.

[20] P. Armitage and G. Berry, Statistical Methods in Medical Research, Blackwell Science, Cambridge, 1994.

[21] C. Niederau, L.D. Ferrell and J.H. Grendell, Caerulein-induced acute necrotizing pancreatitis in mice: protective effects of proglumide, benzotript, and secretin, Gastroenterology 88 (1985), 1192-1204.

[22] C. Niederau, R.A. Liddle, L.D. Ferrell and J.H. Grendell, Beneficial effects of CCK-receptor blockade and inhibition of proteolytic enzyme activity in experimental acute hemorrhagic pancreatitis in mice: evidence for cholecystokinin as a major factor in the development of acute pancreatitis, J. Clin. Invest. 78 (1986), 1056-1063.

[23] C. Niederau, Experimentelle Therapieansätze bei akuter Pankeatitis, in: Erkrankungen des exkretorischen Pankreas, J. Mössner, G. Adler, U.R. Fölsch and M.V. Singer, eds, Fischer, Jena, 1995, pp. 232-245.

[24] M. Otsuki, S. Tani, Y. Okabayashi, T. Nakamura, M. Fujii, T. Fujisawa, S. Baba and H. Itoh, Effect of a new cholecystokinin receptor antagonist CR 1392 on caerulein-induced acute pancreatitis in rats, Pancreas 44 (1989), 237-243.

[25] S. Tani, Y. Okabayashi, T. Nakamura, M. Fujii, H. Itoh and M. Otsuki, Effect of a new cholecystokinin receptor antagonist loxiglumide on acute pancreatitis in two experimental animal models, Pancreas 5 (1990), 284-290.

[26] A.C.C. Wagener, H. Weber, L. Jonas, H. Nizze, M. Strowski, F. Fiedler, H. Printz, H. Steffen and B. Göke, Hyperthermia induces heat shock protein expression protection against cerulein-induced pancreatitis in rats, Gastroenterology 111 (1996), 1333-1342.

[27] C. Wirth, J. Schwuchow and L. Jonas, Internalization of wheat germ agglutinin (WGA) by rat pancreatic cells in vivo and in vitro, Acta Histochem. 98 (1996), 165-172. 


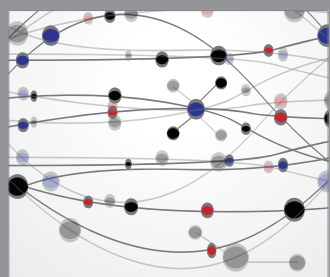

The Scientific World Journal
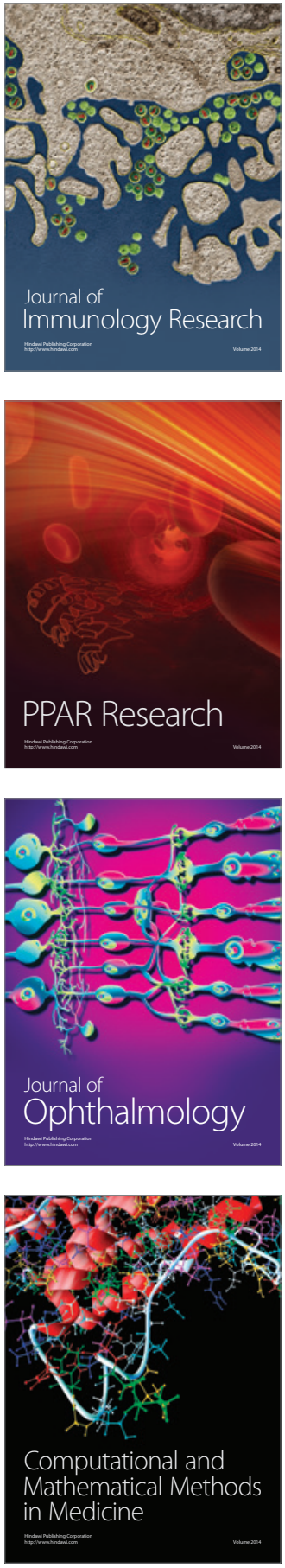

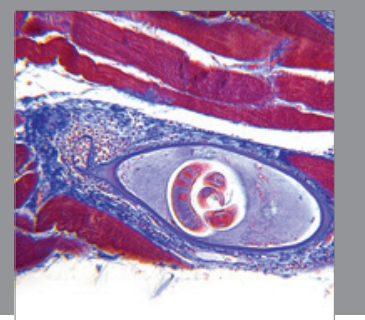

Gastroenterology

Research and Practice
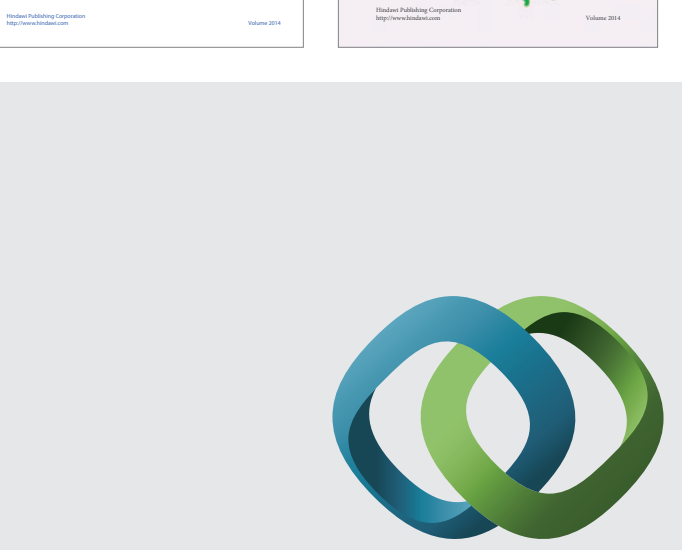

\section{Hindawi}

Submit your manuscripts at

http://www.hindawi.com
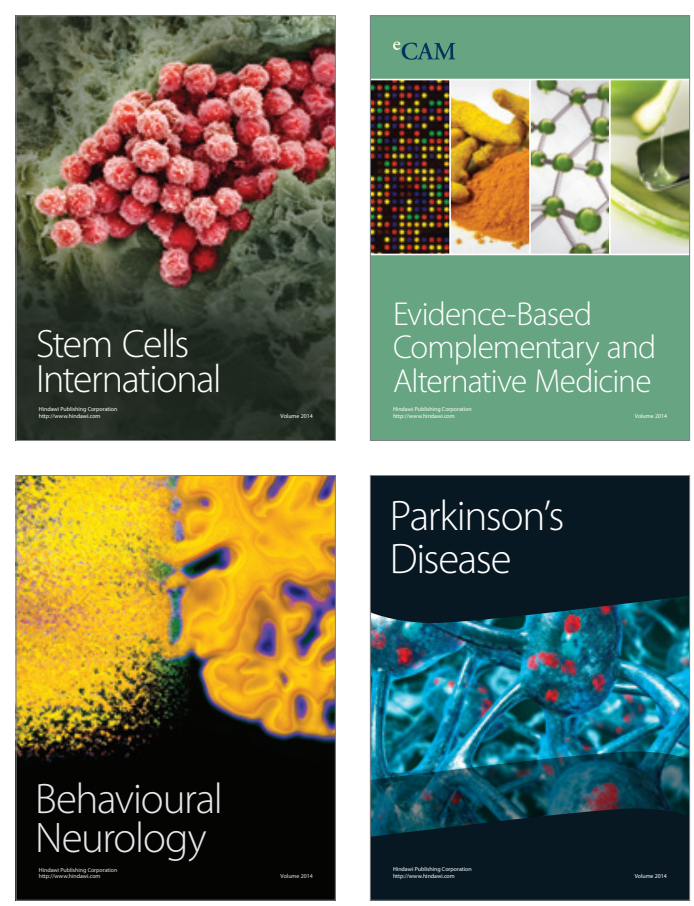

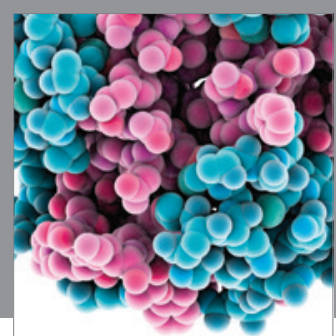

Journal of
Diabetes Research

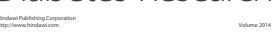

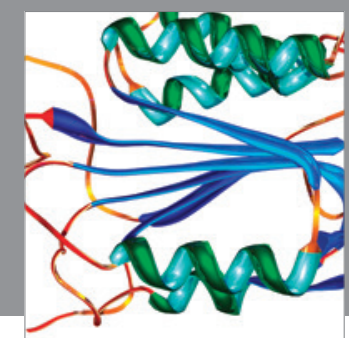

Disease Markers
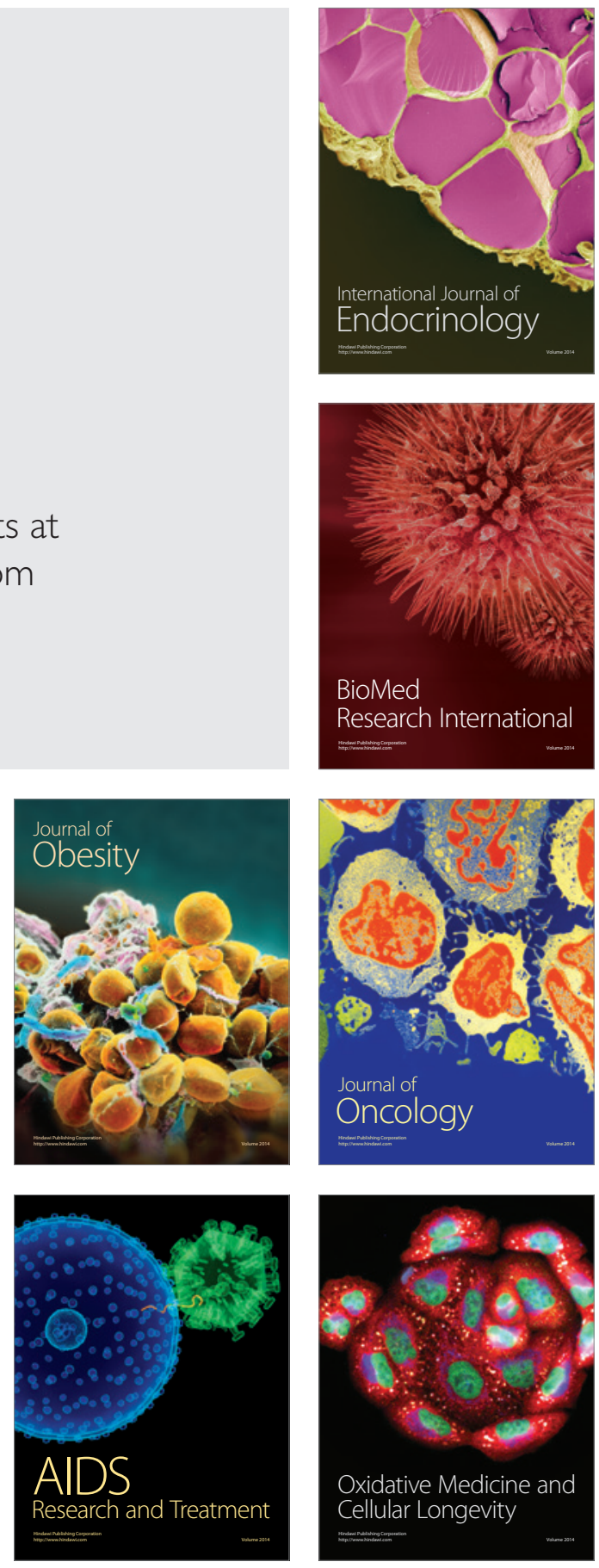